\title{
Recomendações quanto à amamentação na vigência de infecção materna
}

\author{
Recommendations for breastfeeding during maternal infections
}

\author{
Joel A. Lamounier ${ }^{1}$, Zeina S. Moulin², César C. Xavier ${ }^{3}$
}

\section{Resumo}

Objetivo: Revisão da literatura com o enfoque de amamentação e doenças infecciosas maternas, no intuito de contribuir com conhecimentos para decisões a serem tomadas pelo profissional de saúde.

Fontes de dados: Informações foram obtidas em consultas que incluíram livros-texto, normas técnicas, artigos selecionados por meio de busca na base de dados Lilacs e MEDLINE, além de referências específicas.

Síntese dos dados: Nutrizes com doenças infecciosas podem transmitir agentes patogênicos pelo leite materno para a criança. Embora a amamentação confira proteção à criança, ela pode também ser uma importante fonte de infecção. Doenças maternas causadas por vírus, fungos e agentes parasitários podem, em alguns casos, ser transmitidas via leite humano. Para mães com infecções pelo vírus da imunodeficiência humana e vírus T-linfotrópicos humanos tipo I, a recomendação é não amamentar. Nas demais doenças, é necessária uma avaliação cuidadosa, mas, em geral, na maioria dos casos, o aleitamento materno é mantido.

Conclusões: Algumas doenças, principalmente as causadas por vírus, podem ser transmitidas durante a amamentação. O profissional de saúde, ao identificar uma nutriz com infecção viral ativa ou outra doença infecciosa, necessita tomar a decisão de suspender ou não a amamentação, o que pode ser um fato angustiante pelo seu papel fundamental na promoção e estímulo ao aleitamento materno.

J Pediatr (Rio J). 2004;80(5 Supl):S181-S188: Leite humano e infecção, doenças infecciosas da mãe, aleitamento materno e doenças.

\section{Introdução}

O leite humano, além de seus componentes nutritivos, contém, em sua composição, uma complexidade de células,

1. Doutor em Saúde Pública, Universidade da Califórnia, Los Angeles, EUA. Professor titular, Departamento de Pediatria, Faculdade de Medicina, Universidade Federal de Minas Gerais (UFMG), Belo Horizonte, MG. Professor orientador do Programa de Pós-graduação em Saúde da Criança e do Adolescente da UFMG.

2. Mestre em Pediatria pela UFMG. Professora de Pediatria, Faculdade de Medicina, UFMG, Belo Horizonte, MG.

3. Doutor em Pediatria, Faculdade de Medicina da USP, Ribeirão Preto. Professor de Pediatria, Faculdade de Medicina, UFMG. Professor orientador do Programa de Pós-graduação em Saúde da Criança e do Adolescente da UFMG.

Como citar este artigo: Lamounier JA, Moulin ZS, Xavier CC. Recomendações quanto à amamentação na vigência de infecção materna. $J$ Pediatr (Rio J). 2004;80(5 Supl):S181-S188.

\begin{abstract}
Objective: To make a literature review on breastfeeding and maternal infectious diseases in order to contribute with knowledge and information that can aid the pediatrician to decide upon allowing infected mothers to breastfeed their babies or not.
\end{abstract}

Sources of data: Lilacs and MEDLINE databases were searched for books, technical rules and articles on the issue of breastfeeding and infected mothers.

Summary of the findings: Infected lactating mothers can transmit pathogenic agents to their infants. Although breastfeeding protects the child it can also be a dangerous source of infection. Maternal diseases caused by bacteria, virus, fungi and parasites may sometimes be transmitted via human milk. The literature points out that mothers infected with HIV and T-lymphotropic human viruses (type I) should not breastfeed. With other diseases a careful approach should be made, but, in general, breastfeeding is maintained.

Conclusion: The mother who is exposed to infectious diseases may transmit pathogenic agents through the human milk, attention should also be made to milk from milk banks. The healthcare provider must take his/her decision upon suspending breastfeeding - or not, what can be distressful, once he/she has a fundamental role in promoting and stimulating breastfeeding.

J Pediatr (Rio J). 2004;80(5 Sup/):S181-S188: Human milk and infection, mother's infectious illnesses, maternal breast-feeding and infection.

membranas e moléculas que atuam na proteção do recémnascido. Na mulher em lactação, o sistema denominado enteromamário ou broncomamário atua quando os patógenos (bactérias) entram em contato com as mucosas do intestino ou aparelho respiratório e são fagocitados pelos macrófagos. Com isso, desencadeia-se uma ação estimulante nos linfócitos T, promovendo diferenciação dos linfócitos B produtores de imunoglobulinas A (IgA). Os linfócitos migram para a glândula mamária e, com a mediação de citocinas, tornam-se células plasmáticas que produzem uma glicoproteína que é acoplada à IgA, convertendo-se em imunoglobulina A secretória (IgAs). Esta é uma função importante e específica de proteção do recém-nascido conferida pelo leite humano ${ }^{1-5}$. 
O aleitamento materno, pelas inúmeras vantagens que traz tanto para a mãe como para o recém-nascido, é reconhecido como a melhor forma de alimentação da criança. Entretanto, doenças envolvendo tanto a mãe quanto o recém-nascido podem constituir obstáculos para a amamentação. Nessas circunstâncias, é importante que o profissional tenha habilidade, conhecimento técnico e atitude acolhedora para avaliar adequadamente a viabilidade do aleitamento. A nutriz, ao apresentar sintomas de uma doença, geralmente já expôs seu filho ao agente patogênico, e a orientação geral é manter o aleitamento ${ }^{6-}$ 9 . Se a mãe suspende a amamentação quando surgem os sintomas da doença, a proteção ao lactente fica diminuída, aumentando a chance da criança adoecer, pois ela deixará de receber anticorpos específicos e demais fatores de proteção do leite humano.

Não há indicação de suspender a amamentação, mesmo que temporariamente, nas mães com infecção urinária, infecção bacteriana de parede abdominal, episiorrafia, mastite ou outra em que as condições físicas e o estado geral da nutriz não estejam muito comprometidos.

Embora o leite humano contenha anticorpos, células mononucleares e outros fatores de proteção, em algumas doenças maternas ele pode funcionar como possível fonte de infecção para a criança 6,7 . As células mononucleares do leite humano, mesmo promovendo proteção, podem transferir partículas infecciosas da mãe para o lactente. Assim, o profissional de saúde, ao identificar uma nutriz com infecção viral ativa ou outra doença infecciosa, pode ficar angustiado frente ao dilema na tomada de decisão de suspender ou não a amamentação, já que seu papel é o de promover e estimular o aleitamento materno.

Algumas doenças não-infecciosas podem impedir o aleitamento materno temporária ou definitivamente devido à condições físicas da mãe, tais como doenças cardíacas, renais e hepáticas graves, psicose e depressão pós-parto grave ${ }^{10}$.

Nesta revisão, são feitas considerações sobre o manejo em relação à amamentação na presença de doenças maternas comuns causadas por bactérias, vírus, parasitas e fungos.

\section{Infecções por vírus}

Em várias doenças virais maternas, tais como hepatite, herpes vírus, sarampo, caxumba e rubéola, dentre outras, pode haver excreção de vírus no leite humano. Porém, exceto para as infecções causadas pelos retrovírus - vírus da imunodeficiência humana (HIV-1), vírus T-linfotrópicos humanos tipo I (HTLV I) e vírus T-linfotrópicos humanos tipo II (HTLV II) -, a transmissão por essa via tem pouco valor epidemiológico. Na maioria das doenças viróticas maternas, outras fontes de contaminação para o recémnascido devem ser avaliadas antes de se atribuir essa possibilidade apenas ao aleitamento. O risco de transmissão pode estar aumentado nos casos de infecção aguda no momento do parto, uma vez que o leite pode conter elevada concentração de partículas virais e baixos títulos de anticor- pos protetores capazes de neutralizar o agente infeccioso. Portanto, de modo geral, não há contra-indicação formal para amamentação na maioria dos casos de doenças virais, exceto para o grupo dos retrovírus.

A transmissão de retrovírus RNA, incluindo HIV-111,12, HTLV I e HTLV II ${ }^{13}$, já foi demonstrada. O vírus HIV-2 também poder ser transmitido da mãe para o filho, mas o papel do aleitamento na transmissão via leite humano ainda não está bem estabelecido. O vírus Epstein-Barr e herpes vírus 6 podem ser encontrados no leite humano, mas, até o momento, são raros os relatos de crianças amamentadas infectadas por esses vírus. Até certo ponto, é surpreendente que o leite materno não seja mais infectante, especialmente com o volume consumido diariamente pelo lactente em aleitamento materno exclusivo. Portanto, isso leva a supor que devam existir mais fatores de proteção no leite humano além dos já conhecidos.

Uma síntese das infecções virais mais importantes com possibilidade de transmissão do vírus via leite materno para o recém-nascido, bem como das respectivas condutas em relação ao aleitamento materno, está ilustrada na Tabela 1.

Tabela 1 - Infecções maternas virais e conduta na amamentação

\begin{tabular}{ll}
\hline Tipo de vírus & Recomendação \\
\hline Citomegalovírus & Amamentar \\
Hepatite A* & Amamentar \\
Hepatite B & Amamentar \\
Hepatite C* & Amamentar \\
Rubéola & Amamentar \\
Caxumba & Amamentar \\
Herpes simples & $\begin{array}{l}\text { Amamentar, exceto se as lesões } \\
\text { forem na mama }\end{array}$ \\
Varicela & Amamentar, exceto se a infecção \\
& for adquirida entre 5 dias antes \\
& e 3 dias após o parto \\
Sarampo & Suspender amamentação \\
temporariamente & Não amamentar \\
HTLV I & Não amamentar \\
HIV & \\
\hline
\end{tabular}

* Ver comentários no texto.

\section{Infecção pelo HIV}

O HIV é excretado livre ou no interior de células no leite de mulheres infectadas, que podem apresentar ou não sintomas da doença. Cerca de $65 \%$ da transmissão vertical do HIV ocorre durante o trabalho de parto e no parto propriamente dito; os 35\% restantes ocorrem intra-útero, principalmente nas últimas semanas da gestação e por intermédio do aleitamento materno. A carga viral no leite materno é um importante determinante do risco de transmissão14-16. No recém-nascido, a porta de entrada do vírus são as mucosas nasofaríngea e gastrintestinal. Durante 0 aleitamento materno, a transmissão do vírus pode ocorrer em qualquer fase, porém parece ser mais freqüente nas 
primeiras semanas e, especialmente, nas infecções maternas mais recentes. A carga viral no colostro ou leite inicial é significativamente mais elevada que no leite maduro. $\mathrm{O}$ aleitamento misto parece ser de maior risco do que o aleitamento materno exclusivo, pelo maior dano à mucosa gastrintestinal decorrente da alimentação artificial, que favorece a penetração do vírus ${ }^{17}$. O risco adicional de transmissão do vírus pelo leite humano varia de 5 a $20 \%{ }^{18}$. A contaminação via leite materno em mulheres que adquiriram a infecção após o período pós-natal foi verificada em $29 \%(15-53 \%)$ dos casos $10,16,18$. A presença de células infectadas pelo HIV no leite materno por um período superior a 15 dias após o parto é um fator preditivo importante para a infecção da criança ${ }^{17}$.

Retrovírus podem infectar células do epitélio mamário antes mesmo do parto, podendo ser encontrados livres ou infectando monócitos do leite, que correspondem a $50 \%$ das células do leite materno. Essas células podem, potencialmente, transportar vírus da circulação materna ou de tecidos linfóides para o intestino do neonato. Alguns tipos de HIV utilizam receptores de quimocinas para infectar os macrófagos. No entanto, são necessários mais estudos para conhecer com precisão o papel das células do leite humano na infecção pelo HIV19-21.

A utilização de terapêutica anti-retroviral durante a gestação e o parto e sua manutenção em recém-nascidos resulta, mesmo se mantido o aleitamento materno, em redução da transmissão vertical do HIV por até 6 meses após o parto ${ }^{22}$. No entanto, a infecção pelo HIV é uma das poucas situações onde há consenso de que a amamentação deve ser contra-indicada. No Brasil, o Ministério da Saúde 23 recomenda que as mães portadoras do vírus HIV não amamentem. Porém, a Organização Mundial de Saúde (OMS) e o Fundo das Nações Unidas para a Infância (UNICEF) recomendam que, em países pobres, onde doenças como diarréia, pneumonia e desnutrição contribuem substancialmente para elevadas taxas de morbimortalidade infantil, o benefício do aleitamento materno deve ser considerado em relação ao risco da transmissão do vírus HIV. Nesses casos, e na impossibilidade de oferta de uma alimentação artificial adequada, é preferível manter a amamentação, haja vista seus benefícios para o lactente vivendo sob condições precárias ${ }^{15,24,25}$. MuIheres que recebem terapia anti-retroviral combinada apresentam taxas muito baixas de transmissão viral ${ }^{22}$. Informações preliminares de um estudo realizado na África do Sul consideram a possibilidade de reduzir ou prevenir o risco de transmissão pós-natal do HIV se a criança recebe o leite humano por curto tempo ${ }^{14}$. A estratégia seria manter o aleitamento por um período de 4 a 6 meses. Entretanto, a eficácia e a segurança dessa prática ainda não foram demonstradas, e estudos ainda estão em andamento.

Outra possibilidade seria reduzir ou eliminar o HIV do leite humano. Células infectadas pelo vírus podem ser removidas do leite, mas partículas virais são difíceis de eliminar. A inativação do vírus HIV do leite materno pelo processo de pasteurização $\left(62,5{ }^{\circ} \mathrm{C}\right.$ por 30 minutos, seguido de resfriamento rápido) permite que a criança continue a receber o leite materno sem aumentar o risco pós-natal do vírus ${ }^{26}$.

\section{Infecção pelo HTLV}

O HTLV é um vírus da família dos retrovírus, a mesma do HIV. São vírus linfotrópicos de células humanas T1 e T2, denominados de HTLV I e HTLV II. O vírus do tipo I causa principalmente uma modalidade rara de leucemia, mielite e infecção ocular que pode levar à cegueira. O vírus HTLV II não está associado a doença. Podem ser transmitidos pelo sangue, agulhas contaminadas, relações sexuais e de mãe para filho por meio do aleitamento materno. A principal forma de transmissão é vertical, sendo a via pelo aleitamento considerada predominante.

Apesar de afetar uma pequena parcela da população e com possibilidade de desenvolver doenças tardiamente em apenas de 1 a $4 \%$ dos infectados, a ocorrência de retrovírus HTLV tem aumentado na América do Sul, principalmente pela falta de controle sanitário. Como as alterações determinadas por esses retrovírus são graves e não dispõem de terapêutica ou vacina eficazes, a contra-indicação do aleitamento natural nas mulheres portadoras é a principal forma de diminuir sua disseminação vertical.

No Japão, tem-se utilizado o congelamento do leite de mães HTLV I-positivas à temperatura de $-20{ }^{\circ} \mathrm{C}$ como método de inativação do vírus. Porém, o Centers for Disease Control and Prevention (CDC) define que toda mãe infectada pelo HTLV I deve ser aconselhada a não amamentar e não opina sobre o congelamento do leite humano nessa situação. Considera como insuficientes os dados atuais sobre a transmissão do HTLV I em casos utilizando leite materno congelado e descongelado.

A quantidade de células infectadas pelo HTLV I no sangue periférico é muito pequena se comparada com o número de células $T$ infectadas no leite materno, o que explicaria o risco elevado de transmissão viral pelo leite humano. Alguns fatores de risco têm sido considerados na transmissão dos vírus HTLV I e II pelo leite humano: período de aleitamento materno superior a 3 meses, idade materna mais avançada, níveis de antígenos no sangue materno e altos títulos de anticorpos HTLV I na nutriz ${ }^{10,17}$. Entretanto, van Dyke et al. ${ }^{27}$ relatam que a transmissão do vírus HTLV II da mãe para a criança pode ocorrer independentemente do tipo de alimentação desta, em taxas similares àquelas do HTLV I, demonstrando, assim, que a transmissão do vírus para a criança pode ocorrer na ausência de amamentação.

\section{Hepatites A, B e C}

Os vírus das hepatites $\mathrm{A}, \mathrm{B}$ e $\mathrm{C}$ podem ser transmitidos para a criança durante a gravidez, parto ou período pósparto. Os vírus de transmissão oral-fecal, como o da hepatite $A$, têm maior possibilidade de serem transmitidos ao recém-nascido no momento do parto.

Além disso, o vírus da hepatite A pode ser excretado no leite humano de nutrizes na fase aguda da doença. Quando o parto ocorre nessa fase da doença, a criança deve receber imunoglobulina anti-HVA na dose de 0,02 ml/kg como 
profilaxia. Essa conduta é indicada para todas as crianças, independentemente da amamentação, e confere proteção que supera o risco da criança adquirir a doença. Assim, o aleitamento materno não é contra-indicado ${ }^{7}$.

Os vírus das hepatites B e C são transmitidos pelo contato com sangue e secreções genitais. $O$ antígeno de superfície do vírus da hepatite $\mathrm{B}$ ( $\mathrm{HBsAg}$ ) tem sido detectado no leite de mulheres soropositivas para o $\mathrm{HBsAg}$, e é possível que pequenas quantidades de sangue possam ser ingeridas pelo recém-nascido durante amamentação, a partir de lesões nos mamilos, mesmo que pequenas. Mas a maior via de transmissão do vírus da mãe para a criança é a exposição do bebê ao sangue materno, que acontece durante todo o trabalho de parto e no parto 29.

Mãe soropositiva para HBsAg durante a gravidez determina a necessidade de a criança receber a primeira dose da vacina logo após o parto e imunoglobulina hiperimune da hepatite $\mathrm{B}$ (HBIG) na dose de $0,5 \mathrm{ml}$ via intramuscular (IM) nas primeiras 12 horas de vida, aplicadas concomitantemente, mas em locais diferentes. A eficácia dessa conduta é de $95 \%$ e elimina o eventual risco de transmissão pelo leite materno 7,30 .

Quando a mulher não foi testada para o HBsAg ou essa informação não está disponível, o exame deve ser solicitado logo após o parto. Enquanto se aguarda o resultado, o recém-nascido deve receber a primeira dose da vacina. Se o resultado do exame for positivo, a imunoglobulina deve ser aplicada o mais cedo possível, dentro dos primeiros 7 dias após o parto. No entanto, se a pesquisa de HBsAG não for possível, não se justifica dar imunoglobulina para todos os recém-nascidos, já que a vacina isoladamente é bastante eficaz na prevenção da doença em 70 a $90 \%$ dos casos ${ }^{7}$.

No parto de gestante HBsAg-positiva, orienta-se lavar bem o recém-nascido, retirando todo vestígio de sangue ou secreção materna. Por outro lado, mesmo que a mãe apresente fissura mamária com sangramento, não se contra-indica a amamentação.

A Sociedade Brasileira de Pediatria recomenda que recém-nascido pré-termo com peso menor que $2.000 \mathrm{~g} \mathrm{e}$ filho de mãe HBsAg-positiva deve receber o esquema vacinal de quatro doses (ao nascimento, com 1, 2 e 6 meses de vida), além da imunoglobulina ${ }^{30}$. Se o esquema proposto não for iniciado no período neonatal, então a criança deverá receber as três doses habituais de vacina. Em todas as situações, o aleitamento materno deve ser recomendado. $\mathrm{Na}$ mãe com criança menor de 1 ano de idade e hepatite $B$ diagnosticada durante a lactação, a conduta é manter a amamentação e testar a criança para $\mathrm{HBsAg}$, uma vez que ela já foi vacinada ao nascer. Se negativa, deve-se revacinar a criança e seguir as medidas profiláticas para o caso, ou seja, administrar HBIG na dose de $0,04 \mathrm{ml} / \mathrm{kg}$ via IM ou gamaglobulina standard na dose de $0,12 \mathrm{ml} / \mathrm{kg}$ via IM ${ }^{30,31}$.

Apesar do vírus da hepatite $C$ ter sido detectado no leite de mães HCV-positivas, sua transmissão por essa via não foi comprovada. Por isso, a amamentação em mães HCVpositivas não está contra-indicada. Entretanto, a prevenção de fissuras mamilares é muito importante, pois ainda não foi determinado se o contato do bebê com o sangue materno pode favorecer a transmissão da doença. O Comitê de Doenças Infecciosas da Academia Americana de Pediatria recomenda que as mães sejam informadas a respeito do risco teórico, ainda não confirmado, de transmissão do vírus para a criança via leite materno. A decisão de amamentar deve ser particularizada para cada caso, em que pese ao papel da amamentação na vida dessa criança, pois não se sabe ao certo o papel do aleitamento na transmissão desse vírus para a criança7.

\section{Citomegalia}

O citomegalovírus (CMV) pode ser excretado de forma intermitente na saliva, urina, trato genital e leite humano por vários anos após a primoinfecção e na ocorrência de reativação de suas formas latentes. $A$ infecção do lactente ou do feto pode ocorrer a partir de mães com infecções na forma primária ou na reativação e ocorre com mais freqüência durante a passagem pelo canal do parto ou no período pós-natal. Porém, devido à passagem de anticorpos por via placentária, a doença não é comum em recém-nascidos.

Na infecção pós-natal, a relação com amamentação é evidente, embora o vírus possa ser adquirido através do contato com outras pessoas soropositivas que vivem no mesmo domicílio. Estudos mostram que 30\% de filhos de mães soropositivas e amamentadas adquirem a infecção nos primeiros anos de vida, chegando a $70 \%$ dos casos quando o vírus é isolado no leite materno. Entretanto, infecções sintomáticas ou seqüelas tardias não têm sido observadas nos bebês, provavelmente devido à passagem de anticorpos maternos específicos que os protegem contra a doença sistêmica. Parece ser preferível a contaminação precoce da criança amamentada, pois, se ocorrer em período mais tardio da vida, o risco de doença sintomática é maior. Esses dados justificam a não-contra-indicação da amamentação 32,33 .

Porém, atenção especial deve ser dada para prematuros, principalmente os de menor idade gestacional. A decisão de amamentar recém-nascido pré-termo, filho de mãe CMV-positiva, deve ser considerada em termos do risco da transmissão da doença versus os benefícios da amamentação. Os prematuros podem não ter anticorpos protetores e apresentar infecções sintomáticas. No entanto, o vírus pode ser inativado pela pasteurização do leite humano, e a carga viral, reduzida pelo congelamento a $-20{ }^{\circ} \mathrm{C}^{32,33}$.

Trabalho recente com recém-nascidos pré-termo que tiveram infecção adquirida no período pós-natal precoce via leite materno de mãe CMV-positiva não mostrou nenhum comprometimento do desenvolvimento neurológico e de audição na criança. Entretanto, visto o pequeno número de crianças avaliadas, estudos de acompanhamento em prematuros com infecções adquiridas no período pós-natal são necessários ${ }^{34}$.

\section{Varicela}

Mãe que tenha apresentado varicela até 5 dias antes ou 2 dias após o parto pode transmitir a doença à criança em sua forma grave, período com maior risco de viremia. 
Nesses casos, está indicado o isolamento da mãe na fase contagiante das lesões até a fase de crosta, além da administração, o mais precocemente possível, de imunoglobulina específica contra varicela (VZIG) na criança, na dose de 125 unidades IM ou imunoglobulina standard $2 \mathrm{ml}$ em dose única IM, esta última de valor discutível ${ }^{10}$. O recém-nascido deve ficar em observação até o $21^{\circ}$ dia de vida. Também não se sabe se o vírus poderia ser encontrado no leite materno e se poderia infectar a criança. Assim, durante esse período, o leite materno pode ser ordenhado e oferecido ao recém-nascido. Porém, se nesse período o bebê desenvolver a doença, deve-se iniciar o tratamento com aciclovir ${ }^{35}$.

Mãe com varicela cujo início da doença foi há mais de 5 dias antes do parto ou após o terceiro dia pós-parto pode produzir e transferir anticorpos para o recém-nascido tanto por via transplacentária quanto pelo leite materno. Nesse caso, o recém-nascido pode desenvolver a forma leve da doença, não estando indicado nem isolamento, nem profilaxia. A mãe pode amamentar a criança, tomando os cuidados especiais de lavagem das mãos, uso de máscara e oclusão de lesões ${ }^{35}$.

\section{Herpes simples}

O recém-nascido pode ser contaminado com herpes simples intra-útero pela via hematogênica transplacentária, durante o parto (a via mais freqüente) ou no período pós-natal. O risco de contaminação neonatal é maior para infecção primária ou não-primária se ocorrer no último mês da gestação. Porém, na última semana antes do parto, a transmissão é baixa para doença recorrente.

O risco de transmissão do vírus pelo leite materno é muito baixo. No acometimento da nutriz pelo herpes, o aleitamento materno deve ser mantido, exceto quando as vesículas herpéticas estiverem localizadas na mama. Lesões ativas em outras partes do corpo devem ser cobertas, recomendando-se rigorosa higiene da nutriz para que o aleitamento seja mantido.

Cuidados adicionais devem ser tomados quando houver vesículas em face e dedos e com outras fontes de vírus herpes simples, como a gengivoestomatite, em outros familiares. Se houver suspeita ou se for confirmado que o recém-nascido tenha infecção por herpes simples, ele deve ser isolado de outras crianças, mas não de sua mãe. Há relato de caso de criança de 15 meses de idade que foi contaminada com a doença por um irmão de 5 anos com gengivoestomatite. A mãe foi contaminada pela criança em ambos os seios durante a amamentação ${ }^{36}$.

\section{Rubéola}

Doença exantemática aguda causada por vírus que pode ser eliminado pelas secreções respiratórias entre 10 dias antes e 15 após o início do exantema. A maioria dos casos é assintomática ou subclínica, podendo, no entanto, transmitir a infecção. Não há dados que contraindiquem o aleitamento materno em nutrizes com a doença. Também, no caso de vacinação da nutriz contra rubéola, a amamentação pode ser mantida ${ }^{10}$.

\section{Sarampo}

Doença exantemática muito contagiosa causada por vírus transmitido por intermédio de secreções respiratórias poucos dias antes e durante o período da doença. O vírus do sarampo ainda não foi isolado no leite humano, mas, por outro lado, anticorpos específicos são encontrados no leite de mulheres imunizadas. Se confirmada a doença na nutriz, está indicado o uso de imunoglobulina no bebê e isolamento da mãe até 72 horas após o início do exantema. Entretanto, o leite materno ordenhado pode ser dado à criança, porque a IgA secretória começa a ser secretada com 48 horas do início do exantema da mãe $\mathrm{e}^{10}$.

\section{Caxumba}

Doença viral de transmissão por contato direto através de gotículas ou fômites de secreções respiratórias. A infecção é rara em crianças menores de 1 um ano devido à transmissão passiva de anticorpos via placenta. Se a nutriz susceptível contrair a doença, a amamentação deverá continuar, porque a exposição já ocorreu 7 dias antes do desenvolvimento da parotidite e a IgAs do leite humano podem ajudar a minimizar os sintomas da criança ${ }^{10}$.

\section{Infecções por bactérias \\ Tuberculose}

Para mães com tuberculose, as recomendações para amamentação dependem da época em que foi feito o diagnóstico da doença. Segundo a OMS, não há necessidade de separar a mãe da criança e, em circunstância alguma, a lactação deve ser impedida9,37. O bacilo de Koch excepcionalmente é excretado pelo leite materno, e, se houver contaminação do recém-nascido, geralmente a porta de entrada é o trato respiratório. Assim, mãe com tuberculose extrapulmonar não necessita de cuidados especiais para amamentar.

Segundo a Academia Americana de Pediatria, recémnascido de mãe com tuberculose pulmonar em fase contagiante ou bacilífera, sem tratamento ou com menos de 3 semanas de tuberculostáticos no momento do parto, deve ser separado da mãe mas alimentado com o leite humano ordenhado, uma vez que a transmissão geralmente se dá pelas vias aéreas. A mãe deve realizar pesquisas do bacilo álcool-ácido resistente (BAAR) no escarro até sua negativação, quando poderá ter contato com o bebê ${ }^{10}$. Este deve receber quimioprofilaxia com isoniazida na dose de $10 \mathrm{mg} / \mathrm{kg} /$ dia por 3 meses e, então, realizar o teste tuberculínico (PPD). Se o teste for positivo, está indicado rastrear a doença através de exame clínico e radiológico. Se não se detecta infecção ativa, mantêm-se a vigilância e a quimioprofilaxia até o sexto mês, quando se aplica o BCG-ID. Se o PPD for negativo aos 3 meses de idade, a quimioprofilaxia pode ser interrompida e o BCG-ID pode ser aplicado, mantendo-se a vigilância clínica. Em situações onde há risco de não-acompanhamento do bebê em uso de quimioprofilaxia com isoniazida, é mais seguro indicar a vacinação com BCG-ID concomitante 7,17 . 
Segundo a OMS, a amamentação deve ser mantida, porém deve-se diminuir o contato íntimo mãe-filho, além de se tomar os seguintes cuidados: amamentar com máscara ou similar, lavar cuidadosamente as mãos, rastrear os comunicantes, especificamente os domiciliares. Administrar ao recém-nascido hidrazida (INH) na dose de $10 \mathrm{mg} / \mathrm{kg}$ peso, uma vez ao dia, durante 6 meses. Após o término da quimioprofilaxia, vacinar com BCG-ID. A amamentação deve ser mantida durante todas as etapas ${ }^{9,37}$.

Em mãe em fase não-contagiante da tuberculose cujo tratamento foi iniciado há mais de 3 semanas não há restrições quanto ao aleitamento materno, sendo indicado vacinar o bebê com BCG-ID ao nascer. Nos casos em que o diagnóstico de tuberculose materna for feito após o início da amamentação, o lactente deve ser considerado potencialmente infectado e receber quimioprofilaxia.

A amamentação deve ser mantida, pois a administração de drogas tuberculostáticas para o tratamento da mãe não contra-indica o aleitamento.

$\mathrm{Na}$ Tabela 2 estão apresentadas as recomendações da OMS em caso de tuberculose e a respectiva conduta no aleitamento materno, considerando a possibilidade de nãoutilização do PPD.

É importante ressaltar que todas as crianças devem ser monitoradas quanto ao ganho de peso e à saúde. Atenção especial deve ser dada à criança de mãe com fatores de risco para tuberculose multidroga resistente. Nesse caso, a separação mãe/criança pode ser necessária, uma vez que a mãe, nessa condição, possui maior infectividade e demora mais para responder ao regime terapêutico. O aleitamento materno pode ser mantido com leite ordenhado, diminuindo o contato respiratório entre a mãe e a criança ${ }^{17}$.

\section{Hanseníase}

A hanseníase é uma doença infecciosa de curso crônico, alta infecciosidade e baixa patogenicidade. Apresenta um quadro clínico variável, que depende basicamente da resposta imunológica celular do indivíduo. A transmissão da doença ocorre pelo contato pessoal, preferencialmente prolongado, por meio das secreções nasais e da pele. O bacilo pode ser isolado no leite materno nos casos de doença de Hansen não tratada, bem como em pacientes com duração do tratamento inferior a 3 meses com sulfona (dapsona ou clofazamina) ou inferior a 3 semanas com rifampicina. Lesões de pele na mama também podem ser fonte de infecção para o recém-nascido.

Não há contra-indicação para a amamentação se a mãe estiver sob tratamento adequado ${ }^{10}$. O recém-nascido deve ser tratado o mais precocemente possível e simultaneamente com a mãe. As drogas utilizadas são as mesmas da mãe e podem passar para o leite humano em baixas concentrações, não havendo relato de efeitos colaterais graves. A criança deve ser acompanhada e realizar exames clínicos periódicos para a detecção precoce de possíveis sinais da doença. Além disso, são recomendados os seguintes cuidados na amamentação: lavagem rigorosa das mãos, uso de máscara ao manusear a criança e oclusão de lesões nas mamas.

A mãe contagiante ou bacilífera (não tratada ou tratada há menos de 3 meses com sulfona ou 3 semanas com rifampicina) deve evitar contato com o filho, exceto

Tabela 2 - Condutas para o manejo da tuberculose em mães e bebês, de acordo com a época do diagnóstico da infecção ativa na mãe

\begin{tabular}{|c|c|c|c|c|}
\hline \multicolumn{3}{|c|}{$\begin{array}{l}\text { Tuberculose pulmonar materna ativa diagnosticada } \\
\text { antes do parto }\end{array}$} & \multicolumn{2}{|c|}{$\begin{array}{l}\text { Tuberculose pulmonar materna ativa } \\
\text { diagnosticada após o parto }\end{array}$} \\
\hline \multicolumn{2}{|c|}{$>2$ meses antes } & \multirow{2}{*}{$\begin{array}{c}<2 \text { meses antes } \\
-\end{array}$} & \multirow{2}{*}{$\begin{array}{c}<2 \text { meses depois } \\
-\end{array}$} & \multirow{2}{*}{$\begin{array}{c}>2 \text { meses depois } \\
-\end{array}$} \\
\hline $\begin{array}{l}\text { Escarro negativo } \\
\text { antes do parto }\end{array}$ & $\begin{array}{l}\text { Escarro positivo } \\
\text { antes do parto }\end{array}$ & & & \\
\hline Tratar a mãe & Tratar a mãe & Tratar a mãe & Tratar a mãe & Tratar a mãe \\
\hline Amamentar & Amamentar & Amamentar & Amamentar & Amamentar \\
\hline $\begin{array}{l}\text { Não há necessidade } \\
\text { de quimioprofilaxia }\end{array}$ & $\begin{array}{l}\text { Isoniazida para a } \\
\text { criança por } 6 \text { meses }\end{array}$ & $\begin{array}{l}\text { Isoniazida para a } \\
\text { criança por } 6 \text { meses }\end{array}$ & $\begin{array}{l}\text { Isoniazida para a } \\
\text { criança por } 6 \text { meses }\end{array}$ & $\begin{array}{l}\text { Isoniazida para a } \\
\text { criança por } 6 \text { meses }\end{array}$ \\
\hline $\begin{array}{c}\text { BCG ao } \\
\text { nascimento }\end{array}$ & $\begin{array}{l}\text { BCG após o término } \\
\text { da quimioprofilaxia }\end{array}$ & $\begin{array}{l}\text { BCG após o término } \\
\text { da quimioprofilaxia }\end{array}$ & $\begin{array}{l}\text { BCG após o término } \\
\text { da quimioprofilaxia }\end{array}$ & $\begin{array}{c}\text { Se a BCG não foi } \\
\text { dada ao nascimento, } \\
\text { vacinar após o término } \\
\text { da quimioprofilaxia }\end{array}$ \\
\hline
\end{tabular}

Fonte: adaptado das referências 9 e 37. 
para amamentar, usar máscara ou similar, lavar cuidadosamente as mãos antes de manipular a criança e fazer a desinfecção de secreções nasais e lenços ${ }^{10}$.

\section{Sífilis}

A sífilis é uma doença essencialmente transmitida por contato sexual, mas existem outras formas de transmissão, como contato com pessoa com lesões ativas em mucosas, região genital e mamas. Não há evidencias de transmissão pelo leite humano, sem lesões de mama. A nutriz com sífilis primária ou secundária acometendo a mama pode infectar a criança pelo contato das lesões com as mucosas. Se as lesões estão nas mamas, sobretudo na aréola, amamentação ou uso de leite ordenhado está contra-indicado até o tratamento e a regressão das lesões. Com 24 horas após o tratamento com penicilina, o agente infeccioso (espiroqueta) raramente é identificado nas lesões. Assim, não há contra-indicação à amamentação após o tratamento adequado 10,38 .

\section{Brucelose}

Há relato de isolamento da Brucella melitensis no leite humano, bem como de casos de doença em lactentes amamentados exclusivamente ao seio. Isso confirma a possibilidade de a brucelose ser transmitida via leite materno.

$\mathrm{Na}$ fase aguda da doença grave na mãe, geralmente o aleitamento materno deve ser evitado, podendo ser utilizado o leite humano ordenhado e pasteurizado. Assim que a doença for tratada com antimicrobianos e a nutriz apresentar melhora clínica, a amamentação pode ser restabelecida 39,40 .

\section{Infecções por parasitas \\ Malária}

Como a malária não é transmitida entre humanos, a amamentação pode ser mantida se as condições clínicas da mãe permitirem. Não há nenhuma evidência indicando que a malária possa ser transmitida pelo aleitamento materno ${ }^{38}$. Em mães que necessitam tratamento, cloroquina, quinina e tetraciclina são recomendadas. Sulfonamidas devem ser evitadas no primeiro mês de lactação ${ }^{18}$. Portanto, mãe com malária e em lactação pode amamentar durante o tratamento com drogas específicas.

\section{Doença de Chagas}

Nas formas aguda e crônica da doença de Chagas, estudos mostram que o Trypanosoma cruzi pode ser isolado no leite materno. Há relato de um caso de infecção aguda em lactente de 2 meses de idade amamentado por mãe com a doença ${ }^{41}$. Embora possam aparecer seqüelas tardias, a doença aguda no lactente tende a evoluir de forma benigna. Esse fato, juntamente com a raridade da transmissão da doença, justifica a manutenção do aleitamento materno em mulheres com a forma crônica da doença, exceto se houver sangramento e fissura no mamilo42. Nos casos de doença aguda, a nutriz não deve amamentar ${ }^{41,42}$.

Experimentos em laboratório, utilizando amostras de leite humano contaminadas com o protozoário e testadas em diferentes condições, demonstraram que a pasteurização do leite previne a transmissão da doença. Ratos inoculados por via oral e intraperitonial com leite humano contendo o parasita foram contaminados, porém o grupo controle com animais inoculados com leite pasteurizado não foi infectado 43,44 . Estudos realizados com animais de laboratório utilizando-se leite humano aquecido à temperatura de $63^{\circ} \mathrm{C}$ em forno de microondas doméstico ( 7 minutos, $45 \%$ potência) mostrou ser eficaz na redução da transmissão do Trypanosoma cruzi ${ }^{45}$.

\section{Infecções por fungos \\ Paracoccidiomicose}

Doença granulomatosa sistêmica causada por fungo, cuja transmissão se dá provavelmente por via respiratória. Não há contra-indicação para o aleitamento materno se esta doença acometer a nutriz. Entretanto, é importante lembrar que o cotrimoxazol, comumente usado no tratamento, é excretado no leite materno e pode causar efeitos colaterais graves no recém-nascido 38,40 .

\section{Criptococose}

Doença causada por fungo, com distribuição ampla na natureza. Pacientes com deficiência da imunidade celular, incluindo os portadores de HIV/AIDS, são os de maior risco para desenvolver a doença. A transmissão de partículas no meio ambiente é pela via aerossol, não havendo relato da forma inter-humana. Assim, o aleitamento materno não é contra-indicado 38,40 .

\section{Referências}

1. Butler JE. Immunnologic aspects of breastfeeding, antiinfectious activity of breast milk. Semin Perinatol. 1979;3:255-70.

2. Goldman AS. The immune system of human milk: antimicrobial, antiinflamatory and immunomodulation properties. Pediatr Infect Dis J. 1993;12:664-72.

3. Goldman AS. The immunological system in human milk: the past - a pathway to the future. Adv Nutr Res. 2001;10:15-37.

4. Goldman AS. Breastfeeding lessons from the past century. Pediatr Clin North Am. 2001;48:23-5.

5. Goldman AS. Evolution of the mammary gland defense system and the ontogeny of the immunesystem. J Mammary Gland Biol Neoplasia. 2002; 7:277-89.

6. AAP. Breastfeeding and the use of human milk. American Academy of Pediatrics. Work Group on Breastfeeding. Breastfeed Rev. 1998;6:31-6.

7. American Academy of Pediatrics. Committee on Infectious Diseases. Red Book 2000. 25th ed. Elk Grove Village (IL): AAP; 2000.

8. Lamounier JA, Xavier CC, Moulin ZS. Leite materno e proteção à criança. In: Tonelli E, Freire LMS, editores. Doenças infecciosas na infância e adolescência. $2^{a}$ ed. Rio de Janeiro: Medsi; 2000. p. 89-103.

9. Giugliani ERJ. O aleitamento materno na prática clínica. J Pediatr (Rio J). 2000;76(Supl 3):238-52. 
10. Lawrence RM. Transmission of infectious diseases through breast milk and breastfeeding. In: Lawrence RA, Lawrence RM, editors. Breastfeeding: a guide for the medical profession. 5th ed. St. Louis, MO: Mosby; 1999. p. 563-616.

11. AAP. Human milk, breastfeeding, and transmission of human immunodeficiency virus type 1 in the United States. American Academy of Pediatrics Committee on Pediatric AIDS.

12. Read JS. American Academy of Pediatrics Committee on Pediatric AIDS. Pediatrics. 2003;112:1196-205.

13. John-Stewart G, Mbori-Ngacha D, Ekpini R, Janoff EN, Nkengasong J, Read JS, et al. Breast-feeding and transmission of HIV-1. J Acquir Immune Defic Syndr. 2004;35:196-202.

14. Carneiro-Proietti AB, Ribas JG, Catalan-Soares BC, Martins ML, Brito-Melo GE, Martins-Filho AO, et al. Infection and disease caused by the human $T$ cell lymphotropic viruses type I and II in Brazil. Rev Soc Bras Med Trop. 2002;35:499-508.

15. Rollins N, Meda N, Becquet R, Coutsoudis A, Humphrey J, Jeffrey $B$, et al. Preventing postnatal transmission of HIV-1 through breast-feeding: modifying infant feeding practices. J Acquir Immune Defic Syndr. 2004;35:188-95.

16. Coutsoudis A, Pillay K, Spooner E, Coovadia HM, Pembrey L, Newell ML. Morbidity in children born to women infected with human immunodeficiency virus in South Africa: does mode of feeding matter? Acta Paediatr. 2003;92:890-5.

17. Rousseau CM, Nduati RW, Richardson BA, Steele MS, JohnStewart GC, Mbori-Ngacha DA, et al. Longitudinal analysis of human immunodeficiency virus type 1 RNA in breast milk and of its relationship to infant infection and maternal disease. J Inf Dis. 2003; 187:741-7.

18. Succi RCM, Marques SR. Aleitamento materno e transmissão de doenças infecciosas. PRONAP Programa Nacional de Educação Continuada em Pediatria. Sociedade Brasileira de Pediatria, Rio de Janeiro, 2002/2003, Ciclo VI no. 4. p. 9-25.

19. Lawrence RM, Lawrence RA. Given the benefits of breastfeeding, what contraindications exist?. Pediatr Clin North Am. 2001;48:235-51.

20. Goldfarb J. Breastfeeding. AIDS and other infectious diseases. Clin Perinatol. 1993;20:225-43.

21. Ruff AJ. Breastmilk, breastfeeding and transmission of viruses to the neonate. Semin Perinatol. 1994;18:510-6.

22. Ruiz-Extremera A, Salmeron J, Torres C, De Rueda PM, Gimenez $F$, Robles $C$, et al. Follow-up of transmission of hepatitis $C$ to babies of human immunodeficiency virus-negative women: the role of breast-feeding in transmission. Pediatr Infect Dis J. 2000;19:511-6.

23. Mandelbrot L, Le Chenadec J, Berrebi A, Bongain A, Benifla JL, Delfraissy JF, et al. Interaction between zidovudine prophylaxis and mode of delivery in the French perinatal cohort. JAMA. $1998 ; 280: 55-60$.

24. Ministério da Saúde. Secretaria de Vigilância em Saúde. Programa Nacional de DST/AIDS. Recomendações para profilaxia da transmissão vertical do HIV e terapia anti-retroviral em gestantes. Brasília, DF. 2004. Série Manuais No. 46.

25. Kuhn L, Stein Z, Susser M. Preventing mother-to-child HIV transmission in the new millennium: the challenge of breast feeding. Paediatr Perinat Epidemiol. 2004;18:10-6.

26. Ministério da Saúde. Secretaria de Vigilância em Saúde. Programa Nacional de DST/AIDS. Guia de tratamento clínico da infecção pelo HIV em crianças. Brasília, DF. 2004. Série Manuais No 18.

27. Ministério da Saúde. Recomendações Técnicas para Funcionamento de Banco de Leite Humano, $3^{a}$ ed. Brasília: Ministério da Saúde; 1998.

28. van Dyke RB, Heneine W, Perrin ME, Rudolph D, Starszak E, Woods $T$, et al. Mother-to-child transmission of human Tlymphotropic virus type II. J Pediatr. 1995;127:924-8.
29. Hill JB, Sheffield JS, Kim MJ, Alexander JM, Sercely B, Wendel GD. Risk of hepatitis $B$ transmission in breastfed infants of chronic hepatitis B carriers. Obstet Gynecol. 2002;99:1049-52.

30. Sociedade Brasileira de Pediatria. Documento Científico Gastroenterologia. Consenso do Departamento de Gastroenterologia da Sociedade Brasileira de Pediatria; 2004.

31. Figueiredo GM. Programa Nacional para a Prevenção e Controle das Hepatites Virais (PNHV). Ministério da Saúde. Sociedade Brasileira de Pediatria. Documento Cientifico, 2004.

32. Hamprecht K, Maschmann J, Vochem M, Dietz K, Speer CP, Jahn G. Epidemiology of transmission of cytomegalovirus from mother to preterm infant by breastfeeding. Lancet. 2001;357:513-8.

33. Yasuda A, Kimura H, Hayakawa M, Ohshiro M, Kato Y, Matsuura $O$, et al. Evaluation of cytomegalovirus infections transmitted via breast milk in preterm infants with a real-time polymerase chain reaction assay. Pediatrics. 2003;111:1333-6.

34. Vollmer B, Seibold-Weiger K, Schmitz-Salue C, Hamprecht K, Goelz R, Krageloh-Mann I, et al. Postnatally acquired cytomegalovirus infection via breast milk: effects on hearing and development in preterm infants. Pediatr Infect Dis J. 2004;23:322-7.

35. Heuchan AM, Isaacs D. The management of varicella-zoster virus exposure and infection in pregnancy and the newborn period. Med J Aust. 2001;174:288-92.

36. Sealander JY, Kerr CP. Herpes simplex of the nipple: infant-tomother transmission. Am Fam Physician. 1989;39:111-3.

37. World Health Organization. Breastfeeding and maternal tuberculosis. Update 23. Geneve: World Health Organization; 1998.

38. Camelo Jr JS, Motta MSF. Passagens de agentes infecciosos pelo leite materno. In: Del Ciampo LA, Ricco RG, Nogueira de Almeida CA, editores. Aleitamento materno. Passagens e transferências mãe-filho. São Paulo: Editora Atheneu; 2004. p. 43-54.

39. Palanduz A, Palanduz S, Guller K, Guller N. Brucellosis in a mother and her young infant: probably transmission by breastmilk. Int J Inf Dis. 2000;4:55-6.

40. Costa MM, Walker APG, Schechter M. Doenças infecto-contagiosas e amamentação. In: Santos Júnior LA, editores. A mama no ciclo gravídico-puerperal. São Paulo: Editora Atheneu; 2000. p. 151-6.

41. Medina-Lopes MD. Transmission of Trypanossoma cruzi in a case, during lactation, in a non-endemic area. Rev Soc Bras Med Trop. 1988;21:151-3.

42. Bittencourt AL, Sadigursky M, Da Silva AA, Menezes CA, Marianetti MM, Guerra SC, et al. Evaluation of Chagas's disease transmission through breast-feeding. Mem Inst Oswaldo Cruz. 1988;33:37-9.

43. Campos R, Pinto PLS, Moreira AA. Estudo experimental sobre a transmissão da doença de Chagas por meio do leite. Rev Hosp Clín Fac Med S Paulo. 1988;43:146-7.

44. Ferreira CS, Martinho PC, Amato Neto V, Cruz RRB. Pasteurization of human milk to prevent transmission of Chagas disease. Rev Inst Med Trop Sao Paulo. 2001;43:161-2.

45. Ferreira CS, Amato Neto V, Gakiya E, Bezerra RC, Alarcon RSR. Microwave treatment of human milk to prevent transmission of Chagas disease. Rev Inst Med Trop S Paulo. 2003;45:41-2.

Correspondência:

Joel A. Lamounier

Av. Alfredo Balena, 190

CEP 30130-100 - Belo Horizonte, MG

Fone: (31) 3248.9632 